\title{
EFEITO DO TEOR DE MOLIBDÊNIO NAS CURVAS DE ENDURECIMENTO POR PRECIPITAÇÃO E NA RESISTÊNCIA À OXIDAÇÃO A ALTAS TEMPERATURAS DE AÇOS MARAGING DE ULTRA ALTA RESISTÊNCIA MECÂNICA
}

André de Albuquerque Vicente ${ }^{\prime}$ Sérgio Duarte Brandi ' Angelo Fernando Padilha '

\section{Resumo}

Foram estudadas cinco composições não comerciais de aços maraging de ultra alta resistência, dentro de um projeto que visava obter materiais com limite de escoamento por volta de $3 \mathrm{GPa}$. No total foram estudadas cinco corridas com teores variáveis de molibdênio. Foram obtidas as curvas de envelhecimento das ligas solubilizadas e pré-deformadas a frio após solubilização. Estudou-se o efeito da composição química no comportamento de oxidação ao ar a alta temperatura das ligas. Várias técnicas complementares de análise microestrutural foram utilizadas, tais como microscopia óptica, difração de raios $X$ e microdureza Vickers. A variação no teor de molibdênio na faixa de 7,5 a $15 \%$ teve acentuado efeito na temperatura MS e na resistência à oxidação a altas temperaturas. A pré-deformação a frio após a solubilização causou considerável efeito no posterior endurecimento por precipitação.

Palavras-chave: Maraging; Endurecimento por Precipitação; Oxidação; Altas temperaturas.

\section{EFFECT OF CONTENT OF MOLYBDENUM ON THE PRECIPITATION HARDENING CURVES AND ON THE HIGH TEMPERATURE OXIDATION RESISTANCE OF ULTRA HIGH MECHANICAL STRENGTH MARAGING STEELS}

\begin{abstract}
Five non-commercial compositions of ultra high strength maraging steels were studied within a project aiming to obtain materials with yield strength around $3 \mathrm{GPa}$. In total, five alloys with varying amounts of molybdenum were studied. The aging curves for the solubilized and cold worked conditions, were obtained. The effect of chemical composition on the high temperature oxidation resistance of the alloys was studied. Several complementary techniques for microstructural analysis were used, such as optical microscopy, X-ray diffraction and Vickers microhardness. The variation in the molybdenum content in the range from 7.5 to $15 \%$, had a marked effect on the Ms temperature and on the oxidation resistance at high temperatures. The cold work after solubilization caused considerable effect on precipitation hardening phenomena. Keywords: Maraging; Precipitation hardening; Oxidation; High temperature.
\end{abstract}

\section{INTRODUÇÃO}

O termo maraging é uma abreviação de "martensite age hardening", ou seja, martensita endurecida por envelhecimento.

Nos aços maraging o endurecimento é atingido durante o envelhecimento, quando ocorre a precipitação de compostos intermetálicos. Estes compostos intermetálicos elevam sensivelmente a resistência mecânica do material. A matriz martensítica dos aços Maraging é, ao contrário da dos aços carbono, tenaz e dúctil, devido ao seu baixo teor de carbono. Nos aços maraging as reações de precipitação envolvem predominantemente os elementos de liga $\mathrm{Ni}, \mathrm{Ti}$ e Mo [I-3].

'Departamento de Engenharia Metalúrgica e de Materiais, Escola Politécnica da Universidade de São Paulo - EPUSP, São Paulo, SP, Brasil.

E-mail: andrevic6I I@hotmail.com 
A martensita recém formada apresenta dureza entre 30 e $35 \mathrm{HRC}$, sendo considerada relativamente mole. Isto permite usinagem de peças com formas complexas na condição "mole", seguida de endurecimento com um mínimo de distorção $[1,3]$.

Aços maraging comerciais apresentam limites de escoamento entre I50 e $350 \mathrm{Ksi}$ (I030 a $2420 \mathrm{MPa}$ ). Alguns aços maraging experimentais apresentam limites de escoamento da ordem de $500 \mathrm{Ksi}(3450 \mathrm{MPa})$. Estes aços apresentam altos teores de níquel, cobalto e molibdênio e teores de carbono bastante baixos [I-3].

O início das pesquisas para o desenvolvimento de aços maraging comerciais se deu nos anos cinquenta pela "International Nickel Company". As pesquisas realizadas na época resultaram no desenvolvimento de aços maraging com as seguintes composições: 20 a $25 \% \mathrm{Ni}$; $0,3 \% \mathrm{Al}$; $\mathrm{I}, 4 \% \mathrm{Ti}$ e $0,4 \% \mathrm{Nb}$. Estes aços, após o envelhecimento entre 425 e $510^{\circ} \mathrm{C}$, apresentavam boa combinação de resistência e ductilidade para dureza na ordem de 55HRC, entretanto foram abandonados devido sua fragilidade [2].

A martensita escorregada e cúbica de corpo centrado, obtida no sistema ferro-níquel metaestável (Figura I) com simples resfriamento ao ar, é relativamente resistente e bastante tenaz. Tornava-se necessário obter um endurecimento de martensita sem que houvesse perda significativa na sua tenacidade.

Para efeitos práticos, entre 10 e $25 \%$ de níquel, a formação de martensita sempre ocorre porque tempos excessivamente longos são necessários para a formação das fases previstas pelo diagrama de equilíbrio que são ferrita e austenita (Figura I) [4].

O aço maraging com $20 \%$ de níquel possui uma temperatura Ms por volta de $200^{\circ} \mathrm{C}$ sendo, portanto, martensítico à temperatura ambiente. Com tratamento de envelhecimento entre $425-485^{\circ} \mathrm{C}$, a martensita sofre um endurecimento significativo $[3,4]$. Conforme já foi mencionado, este endurecimento é causado pela precipitação de compostos intermetálicos.

Estudos feitos no sistema Fe-Ni por Decker, Eash e Goldman mostraram que a martensita formada neste sistema binário poderia ser endurecida até altos valores com adição de cobalto e molibdênio [2].

O titânio é empregado nos aços maraging com $18 \% \mathrm{Ni}$ como um endurecedor suplementar, uma vez que a maior parte do endurecimento provém da combinação cobalto e molibdênio [4]. Nesses aços, a transformação martensítica sempre se completa quando eles são resfriados à temperatura ambiente, uma vez que que eles apresentam temperaturas Ms entre 200 e $300^{\circ} \mathrm{C}$ [2].

Como já foi mencionado anteriormente e mostrado na Figura 2, a temperabilidade dos aços maraging é excelente e, portanto, mesmo em resfriamento ao ar de peças espessas obtém-se estrutura 100\% martensítica [2].

Os aços maraging são envelhecidos em temperaturas na faixa de 400 a $500^{\circ} \mathrm{C}$, onde ocorre um sensível endurecimento por precipitação. A Figura 3 mostra a variação da dureza do aço maraging $\mathrm{I} 8 \mathrm{Ni}(250)$ em função do tempo para várias temperaturas de envelhecimento. É interessante notar a alta resistência ao super envelhecimento que este aço apresenta para a temperatura de $480^{\circ} \mathrm{C}$.

Através de difração de elétrons em área selecionada, evidenciou-se formação de zonas coerentes (zonas de Guinier-Preston; GP) ricas em Ti e Mo em discordâncias, no início do envelhecimento dos aços maraging [5]. Nestas zonas nucleariam dois tipos de precipitados, os quais seriam os responsáveis pelo endurecimento inicial da matriz. É aceito que estes precipitados são do tipo $\mathrm{Ni}_{3} \mathrm{Mo}$ e $\mathrm{Ni}_{3} \mathrm{Ti}$ sendo as suas estruturas cristalinas ortorrômbica e hexagonal, respectivamente.

Trabalhos anteriores mostram que os átomos de níquel na célula unitária de $\mathrm{Ni}_{3}$ Ti podem ser substituídos por átomos de cobalto e ferro, enquanto os átomos de titânio podem ser substituídos por átomos de molibdênio $[5,6]$.

Portanto, a fórmula geral para estes precipitados seria $(\mathrm{Ni}, \mathrm{Fe}, \mathrm{Co})_{3}(\mathrm{Ti}, \mathrm{Mo})$ sendo que a concentração de Mo e $\mathrm{Ti}$ nestes precipitados seria controlada pelo teor destes elementos de liga.

Nos aços contendo cobalto, após algumas horas de envelhecimento ocorre a precipitação de um outro tipo de precipitado. Esse precipitado era, até pouco tempo atrás, identificado como sendo a fase de Laves $\mathrm{Fe}_{2} \mathrm{Mo}$, sendo ela responsável pelo pico e manutenção da alta dureza destes aços durante o envelhecimento. Nos aços sem cobalto, este precipitado não aparece. Entretanto, a falta de cobalto é compensada pela adição de titânio, a qual promove um maior volume de $\mathrm{Ni}_{3} \mathrm{Ti}$ precipitado que acaba atingindo níveis de dureza compatíveis com os aços contendo cobalto $[5,6]$.

Sha, Cerezo e Smith mostraram em trabalhos com aços maraging C-300 e T-300 que a estequiometria correta do precipitado de ferro e molibdênio é do tipo $\mathrm{Fe}_{7} \mathrm{Mo}_{6}$ (fase $\mu$ ) $[7,8]$. Eles atribuíram esta discórdia quanto ao tipo de precipitado como sendo consequência do método utilizado para identificar esta fase. Até então os precipitados eram identificados por microscopia eletrônica de transmissão (Transmission Electron Microscopy;TEM), difração em área selecionada (Selected Area Diffraction; SAD) no microscópio eletrônico de transmissão e difração de raios $X$, sendo que nos trabalhos de Sha et al. [7-I0] foi utilizada APFIM (Atom-Probe Field-lon Microscopy) a qual possibilitou uma análise em escala atômica. [7 a l0] A perda de resistência nestes aços, após longos períodos de envelhecimento, esta associada principalmente com a reversão da austenita [10].

A reversão da austenita é causada pelo enriquecimento em níquel da matriz cúbica de corpo centrado. A fração volumétrica de austenita aumenta com o aumento dos teores de $\mathrm{Ni}$ e Mo e diminui com o aumento do teor de cobalto e titânio [2].

O papel do titânio é facilmente explicado uma vez que sua adição resulta na precipitação de $\mathrm{Ni}_{3}$ Ti que provoca uma perda de níquel da matriz. Por exemplo: I,4\%Ti em peso empobrecerá a matriz de um aço maraging com $18 \% \mathrm{Ni}$ em peso em cerca de $6 \%$ de $\mathrm{Ni}$, reduzindo assim o teor de níquel para $12 \%$ em peso. Logo, as temperaturas 

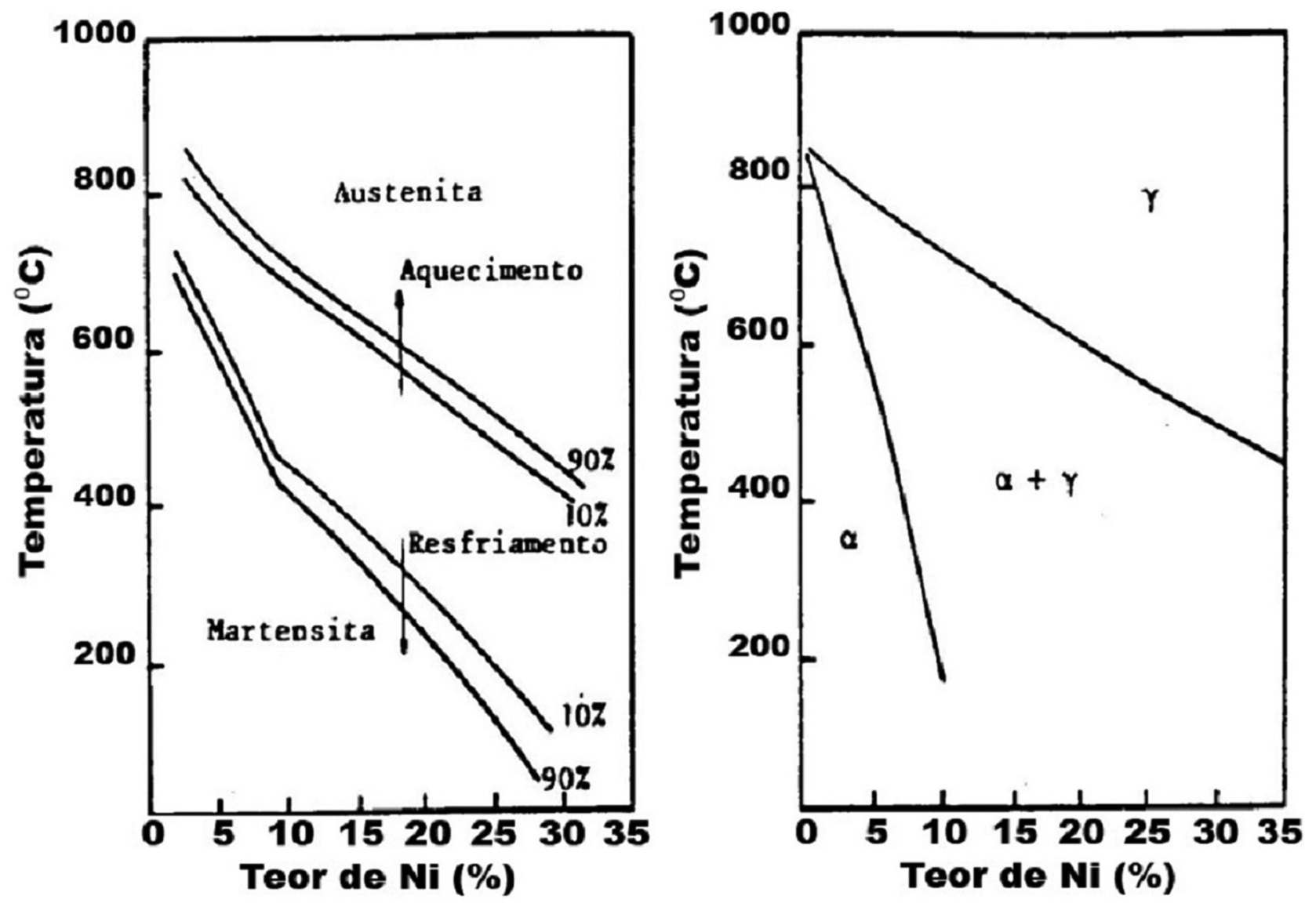

Figura I. Diagrama Fe-Ni metaestável e diagrama Fe-Ni de equilíbrio [I-4].

(a)

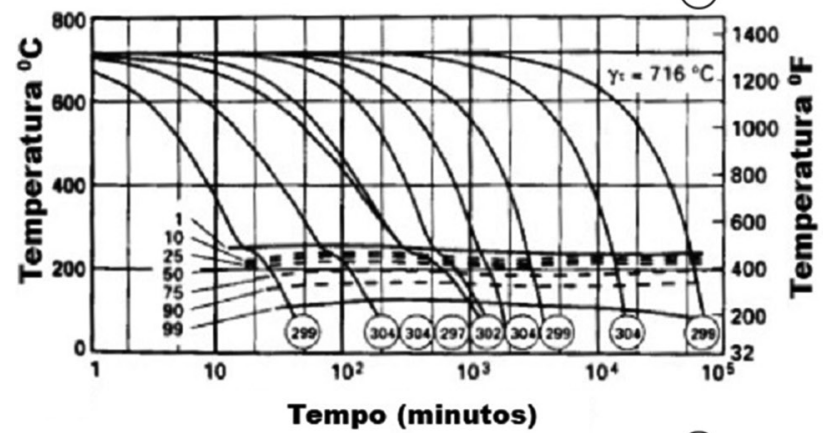

(C)

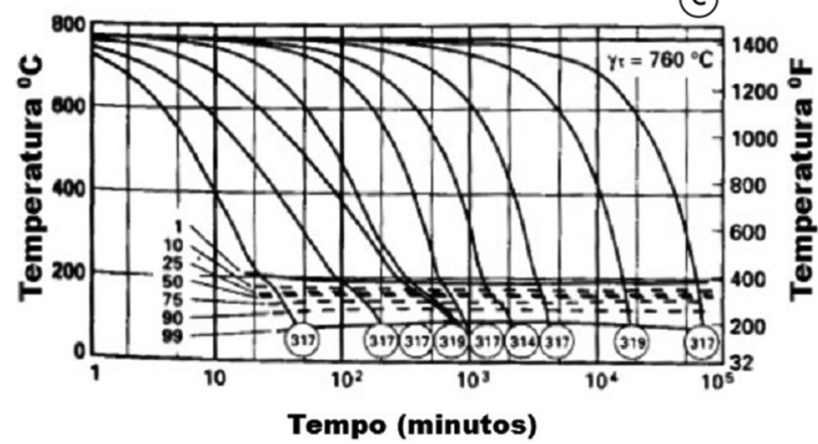

(b)

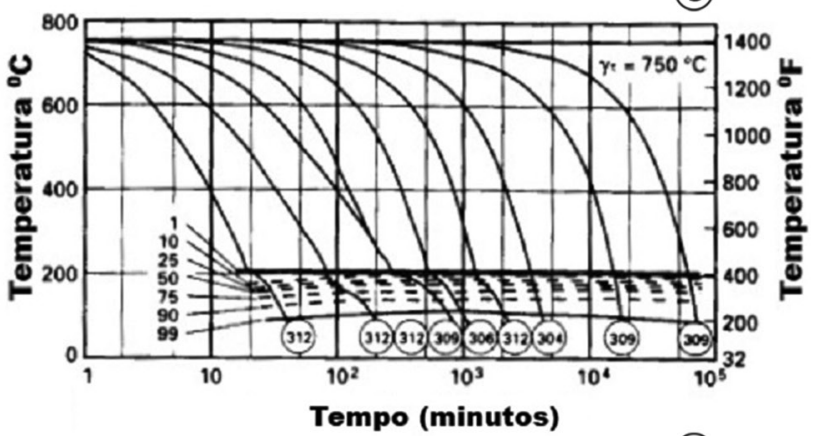

(d)

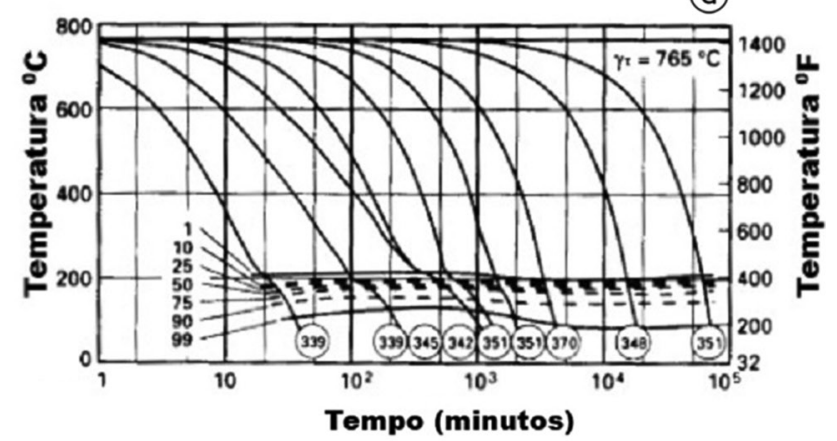

Figura 2. Curvas de resfriamento contínuo de aços maraging solubilizados a $845^{\circ} \mathrm{C}$ por $20 \mathrm{~min}$. (a) $18 \mathrm{Ni}(200)$. (b) $18 \mathrm{Ni}(250)$. (c) $18 \mathrm{Ni}(300)$. (d) $18 \mathrm{Ni}(350)[2]$. 
As e Af aumentam diminuindo o percentual de austenita revertida. [2] Adições de até $8 \%$ de cobalto aumentam a temperatura Ms e portanto diminuem o teor de austenita revertida. A partir de $8 \%$ de cobalto a temperatura Ms diminui e portanto aumenta o teor de austenita revertida [2].

O efeito mais importante do cobalto é diminuir a solubilidade do molibdênio e, portanto, promover uma precipitação mais intensa de $\mathrm{Fe}_{7} \mathrm{Mo}_{6}$. Esta precipitação aumenta o teor de níquel da matriz devido à perda de ferro durante a precipitação $[6,10]$.

Para níquel e molibdênio a explicação é lógica uma vez que altos teores de níquel diminuem as temperaturas Ms, Mf, As e Af e maiores teores de molibdênio aumentam a fração volumétrica de $\mathrm{Fe}_{7} \mathrm{Mo}_{6}$ e consequentemente aumentam o teor de níquel equivalente da matriz.

Para melhor entender todas as reações que ocorrem durante o tratamento térmico dos aços maraging é importante discutir o papel de cada elemento de liga entendendo, assim, o motivo de sua adição.

Titânio (Ti): O titânio aparece como um dos mais ativos elementos de liga nos aços maraging. Ele precipita intensivamente, rapidamente e completamente durante o envelhecimento e diminui a fração volumétrica de austenita revertida [10].

Molibdênio (Mo): A precipitação de molibdênio é extremamente influenciada pela presença de outros elementos de liga como $\mathrm{Ti}$ e Co. Existem várias evidências de que a presença de cobalto aumenta a atividade do molibdênio e, consequentemente, o potencial para que ocorra a precipitação. Em aços sem cobalto, a precipitação do Mo é muito mais lenta, e para tempos de tratamentos térmicos usuais, esta precipitação praticamente não ocorre. No caso do titânio, o efeito é mais sutil sendo possível verificá-lo apenas no início do envelhecimento. $O$ titânio precipita primeiro formando a fase $\mathrm{Ni}_{3} \mathrm{Ti}$ e posteriormente o molibdênio segrega enriquecendo o precipitado [10].

Silício (Si): O silício é considerado uma impureza nos aços maraging, pois afeta as propriedades mecânicas destes aços de forma negativa [10].

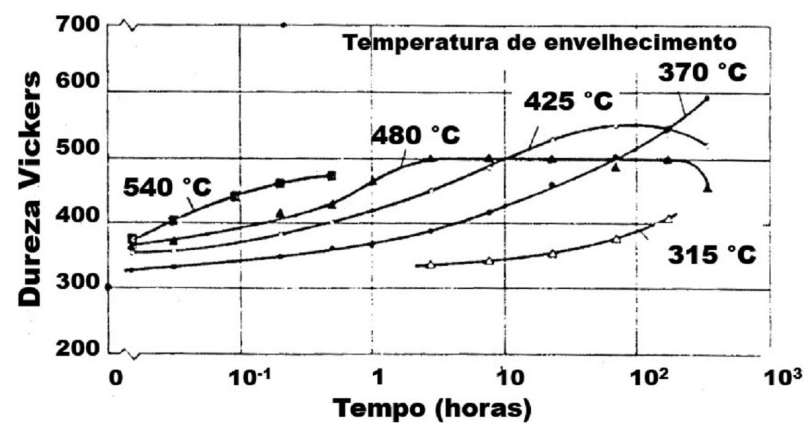

Figura 3. Variação da dureza do aço maraging $I 8 \mathrm{Ni}(250)$ em função do tempo para várias temperaturas de envelhecimento [I].
Manganês (Mn): O Manganês é usado para substituir o níquel no sistema Fe-Mn-Co-Mo, entretanto, o precipitado que ele forma é muito diferente dos precipitados de níquel [I0].

Níquel (Ni): $O$ teor de níquel é extremamente importante no controle do processo de reversão da austenita. A austenita revertida possui um maior teor de níquel em relação à matriz, entretanto os precipitados ricos em níquel formam-se muito antes da austenita por questões cinéticas. Logo a reversão da austenita é controlada pelo teor de níquel da matriz após o endurecimento por precipitação e não pelo teor de níquel nominal do aço [10].

Cobalto (Co): O cobalto acaba agindo indiretamente sobre dois fenômenos: i) ativa a precipitação da fase $\mu$ $\left(\mathrm{Fe}_{7} \mathrm{Mo}_{6}\right)$ aumentando a atividade do $\mathrm{Mo}$; ii) influi na reversão da austenita, podendo tanto aumentá-la quanto diminuí-la dependendo do caso [10].

\section{OBJETIVOS DO TRABALHO}

O presente trabalho tem como objetivos o estudo das curvas de envelhecimento e o estudo comparativo da oxidação ao ar a alta temperatura $\left(1250^{\circ} \mathrm{C}\right)$ de cinco corridas de aços maraging do tipo $\mathrm{Fe}-14 \% \mathrm{Co}-13,5 \% \mathrm{Ni}-7,5$ a I5\% Mo - Ti - Al.

Deve-se mencionar que as corridas pesquisadas no presente trabalho são baseadas em trabalho anterior, no qual foram obtidos, após tratamentos termomecânicos adequados, limites de escoamento acima de $3 \mathrm{GPa}$ [I I].

\section{MATERIAIS E MÉTODOS}

A Tabela I apresenta as composições químicas das cinco corridas estudadas:

As 5 ligas foram fundidas e caracterizadas pelo Grupamento de Metalurgia do IPT. Os tratamentos térmicos de homogeneização foram realizados em forno mufla, sem atmosfera controlada, a $1250^{\circ} \mathrm{C}$ por 5 horas.

Tabela I. Composições químicas dos aços maraging estudados (\% em peso) $[12,13]$

\begin{tabular}{|c|c|c|c|c|c|}
\hline \multirow{2}{*}{ Corrida } & SVI44 & SVI39 & SVI40 & SVI4I & SVI42 \\
\hline & Liga I & Liga 2 & Liga 3 & Liga 4 & Liga 5 \\
\hline C & $0,021 \%$ & $0,014 \%$ & $0,024 \%$ & $0,021 \%$ & $0,023 \%$ \\
\hline $\mathrm{Si}$ & $0,190 \%$ & $0,060 \%$ & $0,080 \%$ & $0,060 \%$ & $0,150 \%$ \\
\hline$M n$ & $0,220 \%$ & $0,030 \%$ & $0,050 \%$ & $0,040 \%$ & $0,160 \%$ \\
\hline Co & $14,49 \%$ & $14,27 \%$ & $15,35 \%$ & $15,21 \%$ & $14,96 \%$ \\
\hline $\mathrm{Ni}$ & $12,61 \%$ & $14,1 \mid \%$ & $13,08 \%$ & $14,06 \%$ & $13,40 \%$ \\
\hline $\mathrm{Al}$ & $<0,01 \%$ & $0,01 \%$ & $0,05 \%$ & $0,04 \%$ & $0,06 \%$ \\
\hline Mo & $11,12 \%$ & II,40\% & II,30\% & $15,02 \%$ & $7,51 \%$ \\
\hline $\mathrm{Ti}$ & $0,06 \%$ & $0,40 \%$ & $0,88 \%$ & $0,24 \%$ & $0,25 \%$ \\
\hline
\end{tabular}


Os tratamentos térmicos de solubilização foram realizados em forno mufla, sem atmosfera controlada, a $820^{\circ} \mathrm{C}$ por I hora.

Foram preparados corpos de prova das cinco corridas a partir de material laminado nos estados solubilizado e encruado. A temperatura de envelhecimento foi de $480^{\circ} \mathrm{C}$. Os tempos de envelhecimento foram 15 minutos, 30 minutos, I hora, 2 horas, 4 horas, 8 horas e 96 horas. Foram feitas oito medidas de dureza Brinell com carga 187,5 Kgf e esfera de 2,5 $\mathrm{mm}$ por corpo de prova.

Foram realizados ensaios de oxidação ao ar a $1250^{\circ} \mathrm{C}$ por 5 horas visando simular as condições do tratamento térmico de homogeneização.

Não foi possível o uso de termo-balanças para efetuar-se ensaios de oxidação uma vez que a reatividade das amostras é bastante acentuada a alta temperatura reagindo com as hastes de quartzo. As amostras foram colocadas em cadinhos de porcelana e apoiadas em placas de alumina. Os conjuntos (amostra+cadinho+placa) foram pesados em balança analítica antes e depois dos ensaios.

As amostras utilizadas para os ensaios de oxidação foram obtidas através de corte de lingotes das respectivas ligas. Utilizando-se equipamento de corte da marca Isomet, modelo Precision Saw 1000, e disco de diamante foi possível obter corpos de prova prismáticos.

Na preparação metalográfica, empregou-se o polimento manual convencional utilizando-se lixas d'água $(180,220$, 320,400 e 600 mesh) e pasta de diamante $(6 \mu \mathrm{m}$ e I $\mu \mathrm{m})$ com o objetivo de padronizar-se o acabamento superficial das amostras.

Para revelação das microestruturas escolheu-se o reagente Kalling $\left(150 \mathrm{ml} \mathrm{H}_{2} \mathrm{O}+50 \mathrm{ml} \mathrm{HCl}+25 \mathrm{ml} \mathrm{HNO}_{3}\right.$ $+\mathrm{Ig} \mathrm{CuCl}$ ) que revelou de forma satisfatória a morfologia da martensita e a microssegregação e, parcialmente, contornos de grão.

Todas as amostras foram observadas em um microscópio óptico.

\section{RESULTADOS E DISCUSSÃO}

As Figuras 4 e 5 abaixo apresentam as curvas de envelhecimento a $480^{\circ} \mathrm{C}$ das cinco composições de aços maraging estudadas, para duas condições iniciais: solubilizada; e solubilizada e encruada.

As curvas de envelhecimento não apresentaram comportamento clássico com máximo bem definido. Em alguns casos foram detectadas evidências de mais de um máximo. A ausência de super envelhecimento ("overaging") foi uma constante para todas as corridas.

O comportamento descrito acima evidencia que as reações de precipitação dos aços maraging são complexas e seu estudo exige técnicas experimentais complementares [5-10].

Por outro lado, a deformação a frio aplicada após solubilização e antes do tratamento térmico de precipitação apresentou efeito claro e acentuado. O material encruado endurece mais rápido e atinge valores de dureza mais altos que o material solubilizado. Os defeitos cristalinos

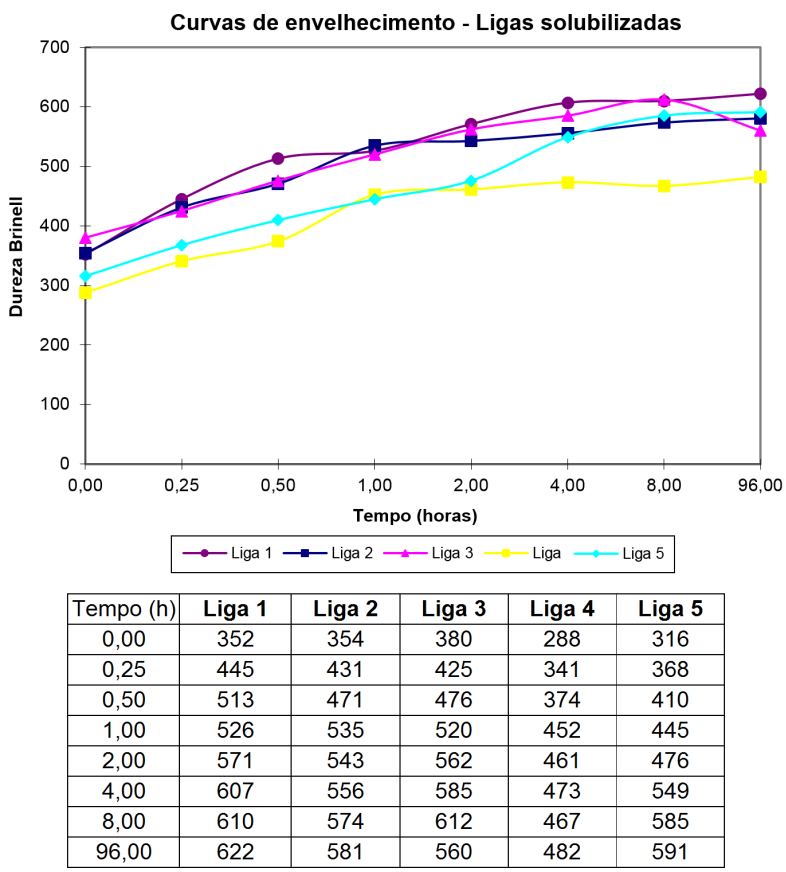

Figura 4. Curvas de endurecimento por precipitação das Liga I (corrida SV 144), Liga 2 (Corrida SV I39), Liga 3 (Corrida SV I40), Liga 4 (Corrida SV I4I) e Liga 5 (Corrida SV I42) solubilizadas a $820^{\circ} \mathrm{C}$ por I hora e envelhecidas a $480^{\circ} \mathrm{C}$ [I2]

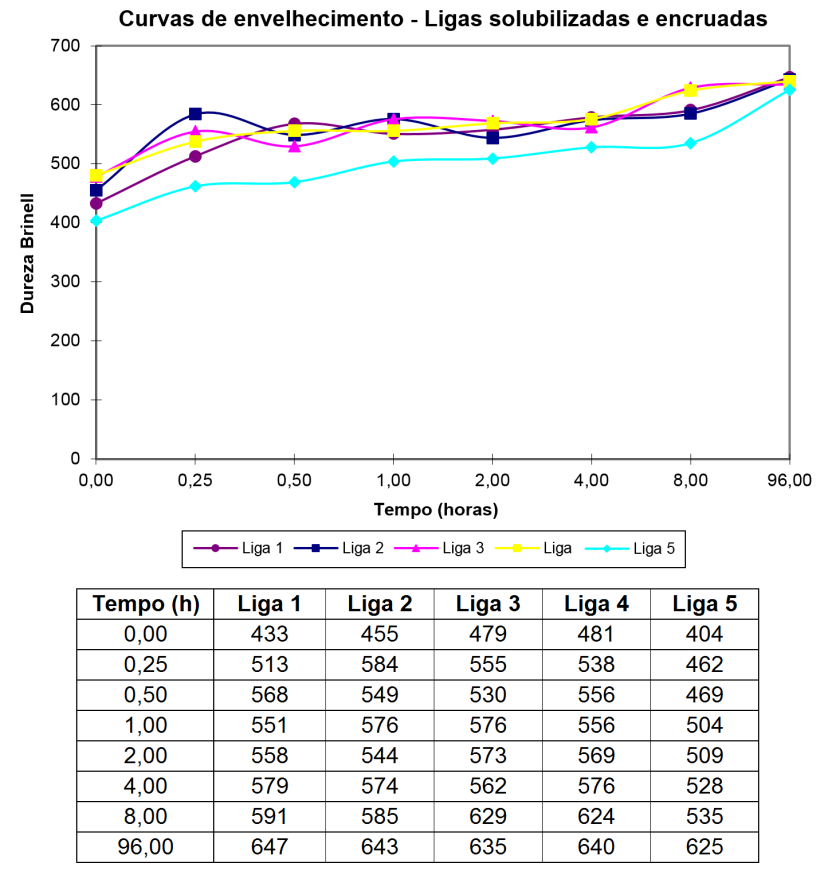

Figura 5. Curvas de endurecimento por precipitação das Liga I (corrida SV 144), Liga 2 (Corrida SV I39), Liga 3 (Corrida SV I40), Liga 4 (Corrida SV I4I) e Liga 5 (Corrida SV I42) solubilizadas a $820^{\circ} \mathrm{C}$ por I hora e encruadas, e envelhecidas a $480^{\circ} \mathrm{C}$ [12]. 
introduzidos durante a deformação a frio aceleram a difusão e oferecem mais sítios para a nucleação de precipitados, levando a distribuições mais finas e efetivas quanto ao endurecimento das ligas $[12,13]$.

Nos diagramas ferro-níquel de equilíbrio e metaestável, mostrados na Figura I, observa-se que a martensita, quando aquecida dentro do campo bifásico do diagrama de equilíbrio, decompõe-se em ferrita e austenita por um processo controlado por difusão [ 12$]$. Durante o resfriamento, torna a ser válido o diagrama metaestável e, dependendo do teor de níquel da austenita que reverteu, esta pode ficar retida à temperatura ambiente ou transformar-se parcial ou totalmente em martensita [12].

Sabe-se da literatura que o molibdênio apresenta o efeito de abaixar a temperatura Ms segundo a Equação I [14]:

$$
\begin{aligned}
& \mathrm{Ms}=539-423(\mathrm{C})-30,4(\mathrm{Mn})-17, \\
& 7(\mathrm{Ni})-12,1(\mathrm{Cr})-7,5(\mathrm{Mo})
\end{aligned}
$$

Tal efeito é confirmado neste trabalho, de forma qualitativa, com auxílio de análise por difração de raios $X$, conforme ilustram os difratogramas da Figura 6. A liga 4, d) na Figura 6 abaixo, foi a única liga em estudo a apresentar picos de austenita bem definidos na condição homogeneizada. Esta liga apresenta $15,02 \%$ de molibdênio, sendo a liga mais rica neste elemento químico.

A análise quantitativa comprovou a importância do molibdênio na resistência à oxidação destes aços.

Tal resultado é confirmado com a análise termogravimétrica. A Tabela 2 mostra a variação de massa dos conjuntos (amostra+cadinho+placa) para as cinco corridas estudadas.

$\mathrm{Na}$ Tabela 2 verifica-se que a liga 4 apresentou a menor variação de massa $(6,4 \%)$, ou seja, a melhor resistência à oxidação das 5 corridas estudadas.

Já a liga 5 apresentou a maior variação de massa $(15,2 \%)$, ou seja, a pior resistência à oxidação das 5 corridas estudadas.
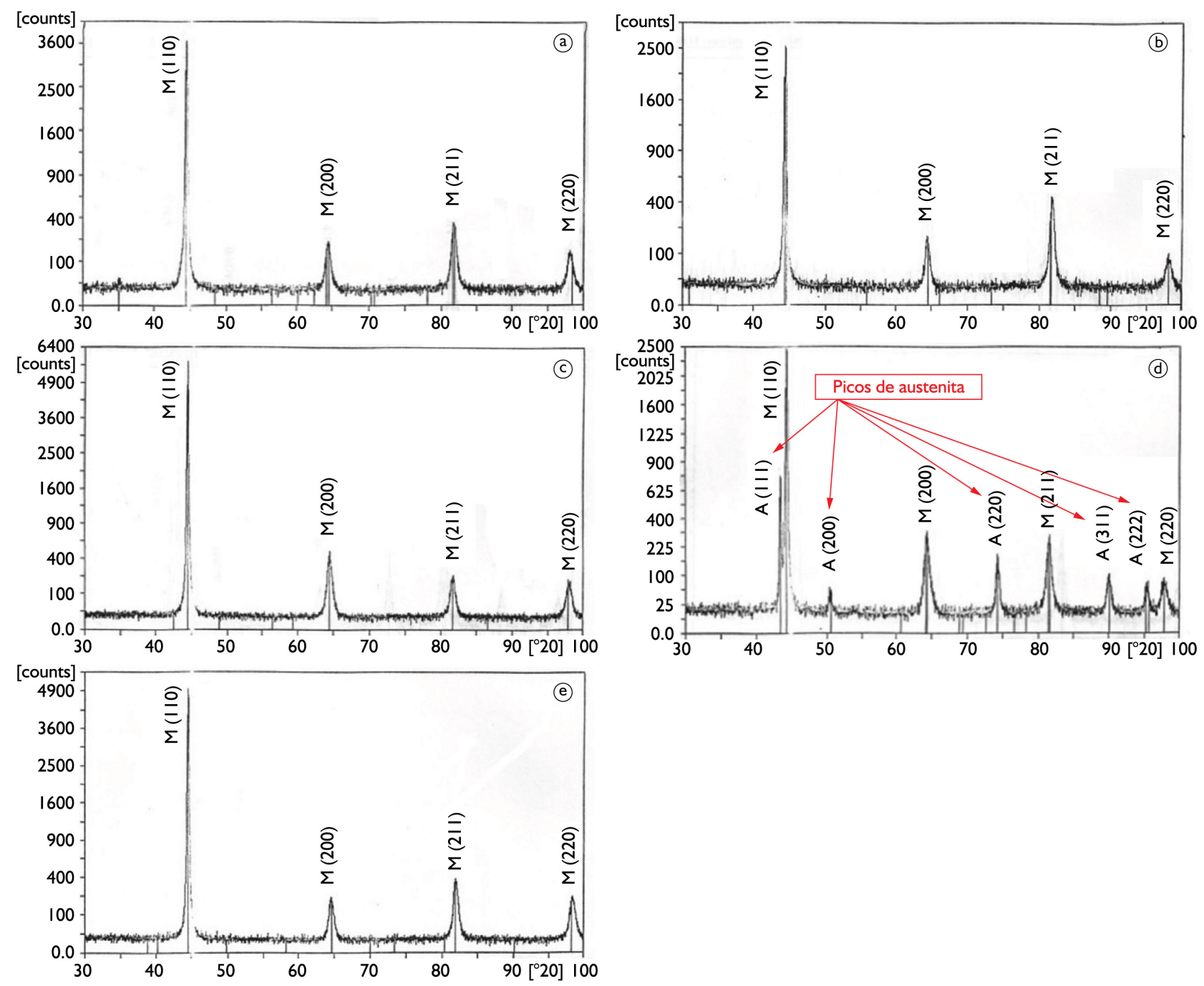

Figura 6. Difratogramas das a) Liga I (corrida SV I44), b) Liga 2 (Corrida SV I39), c) Liga 3 (Corrida SV I40), d) Liga 4 (Corrida SV I4I) e e) Liga 5 (Corrida SV 142), homogeneizadas $1250^{\circ} \mathrm{C}$ por 5 horas [12] . 
Tabela 2. Resultado dos ensaios de oxidação ao ar a $1250^{\circ} \mathrm{C}$ por $5 \mathrm{~h}$ [13]

\begin{tabular}{ccccc}
\hline Liga & $\begin{array}{c}\text { Massa } \\
\text { inicial (g) }\end{array}$ & $\begin{array}{c}\text { Massa } \\
\text { Final (g) }\end{array}$ & $\begin{array}{c}\text { Variação de } \\
\text { massa (g) }\end{array}$ & $\begin{array}{c}\text { Variação de } \\
\text { massa (\%) }\end{array}$ \\
\hline I & 22,0619 & 22,5855 & 0,5236 & 10,7 \\
2 & 23,2312 & 23,5967 & 0,3655 & 7,6 \\
3 & 22,5406 & 22,9442 & 0,4036 & 8,3 \\
4 & 22,1460 & 22,4696 & 0,3236 & 6,4 \\
5 & 22,9450 & 23,6635 & 0,7185 & 15,2 \\
\hline
\end{tabular}

Não foi possível o uso de termo-balanças para efetuar-se ensaios de oxidação uma vez que a reatividade das amostras é bastante acentuada a alta temperatura reagindo com as hastes de quartzo da TG.

Vários materiais refratários foram testados como apoio às amostras para o ensaio de oxidação $a$ alta temperatura. A alumina $\mathrm{Al}_{2} \mathrm{O}_{3}$ apresentou os melhores resultados quanto à reatividade $\mathrm{a}$ alta temperatura com as ligas estudadas.

Uma caracterização preliminar por difração de raios $x$ dos óxidos formados mostrou que o óxido predominante é do tipo $\mathrm{Fe}_{2} \mathrm{O}_{3}$ (fichas JCPDS 4-755 e 13-534).

Deve-se mencionar que as fases presentes em frações volumétricas menores que $5 \%$ dificilmente são detectadas por esta técnica.

Uma identificação mais detalhada dos óxidos formados em função da espessura sugere a formação de três camadas de óxidos. Verificou-se uma camada externa rica em $\mathrm{Fe}_{2} \mathrm{O}_{3}$ seguida de uma camada duplex referente a região de oxidação interna acentuada e uma região de oxidação interna pouco acentuada. Nesta região duplex encontrou-se grande quantidade de óxidos do tipo $\mathrm{Fe}_{2} \mathrm{O}_{3}$ dispersos em uma matriz metálica.

Greyling et al. [15] encontraram $\mathrm{Fe}_{2} \mathrm{O}_{3}$ como o principal óxido formado para a oxidação ao ar a temperaturas entre 300 e $600^{\circ} \mathrm{C}$ de aços Maraging do tipo I8Ni(300).

As Figuras 7 a $1 \mathrm{I}$ apresentam as micrografias das amostras de oxidação das 5 ligas após ensaio de oxidação ao ar a $1200^{\circ} \mathrm{C}$ por 5 horas; mesmas condições do tratamento térmico de homogeneização utilizado nos lingotes.

O molibdênio afetou acentuadamente a resistência à oxidação dos aços estudados.

A análise qualitativa, através de microscopia óptica, revelou que a liga 4 apresenta uma fina camada de óxido após o tratamento de homogeneização a $1250^{\circ} \mathrm{C}$ por 5 horas. Já a liga 5 apresenta oxidação bastante acentuada após o tratamento de homogeneização. A liga 5 apresenta 7,51\% de molibdênio, sendo a liga mais pobre neste elemento químico. As ligas I, 2 e 3 estudadas apresentaram comportamentos muito parecidos quanto a oxidação, uma vez que contêm teores de molibdênio da ordem de II,20\%.
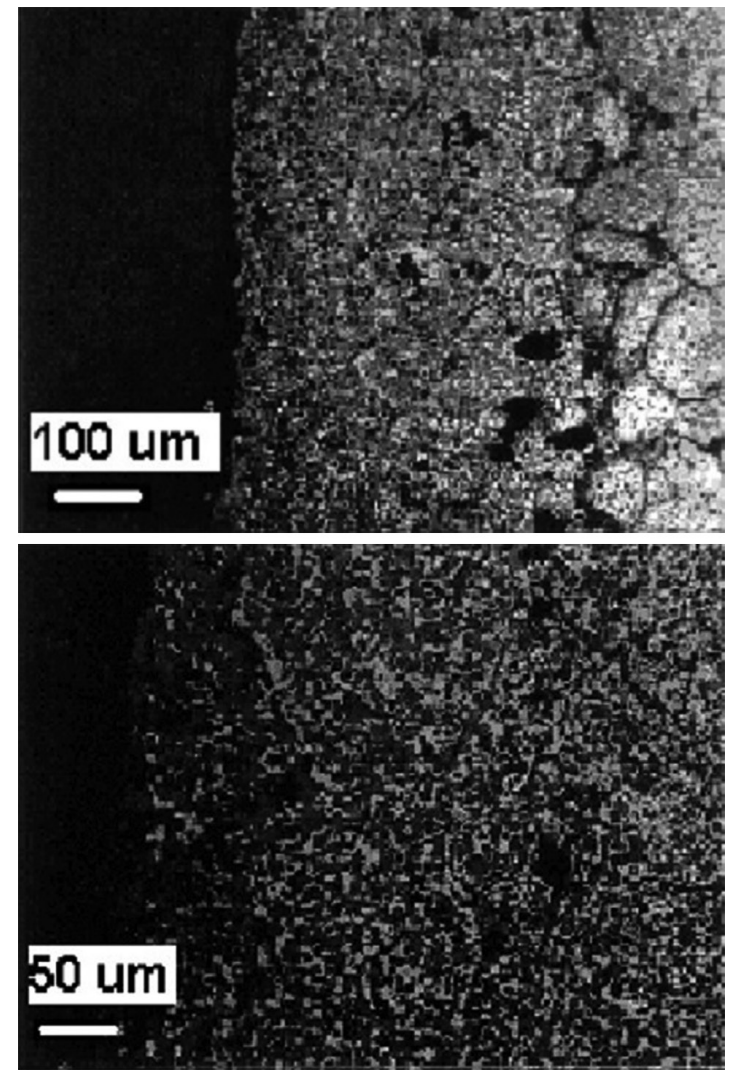

Figura 7. Micrografias da seção transversal da amostra de oxidação da liga I após ensaio de oxidação ao ar a $1200^{\circ} \mathrm{C}$ por 5 horas $[12,13]$.
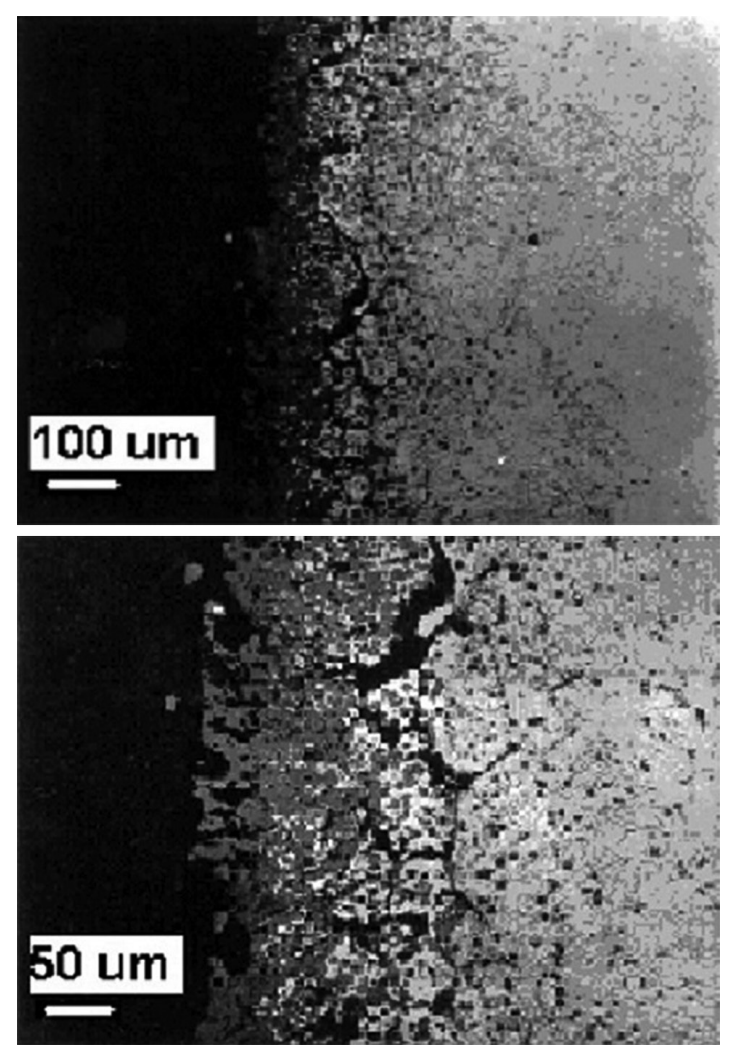

Figura 8. Micrografias da seção transversal da amostra de oxidação da liga 2 após ensaio de oxidação ao ar a $1200^{\circ} \mathrm{C}$ por 5 horas $[12,13]$. 

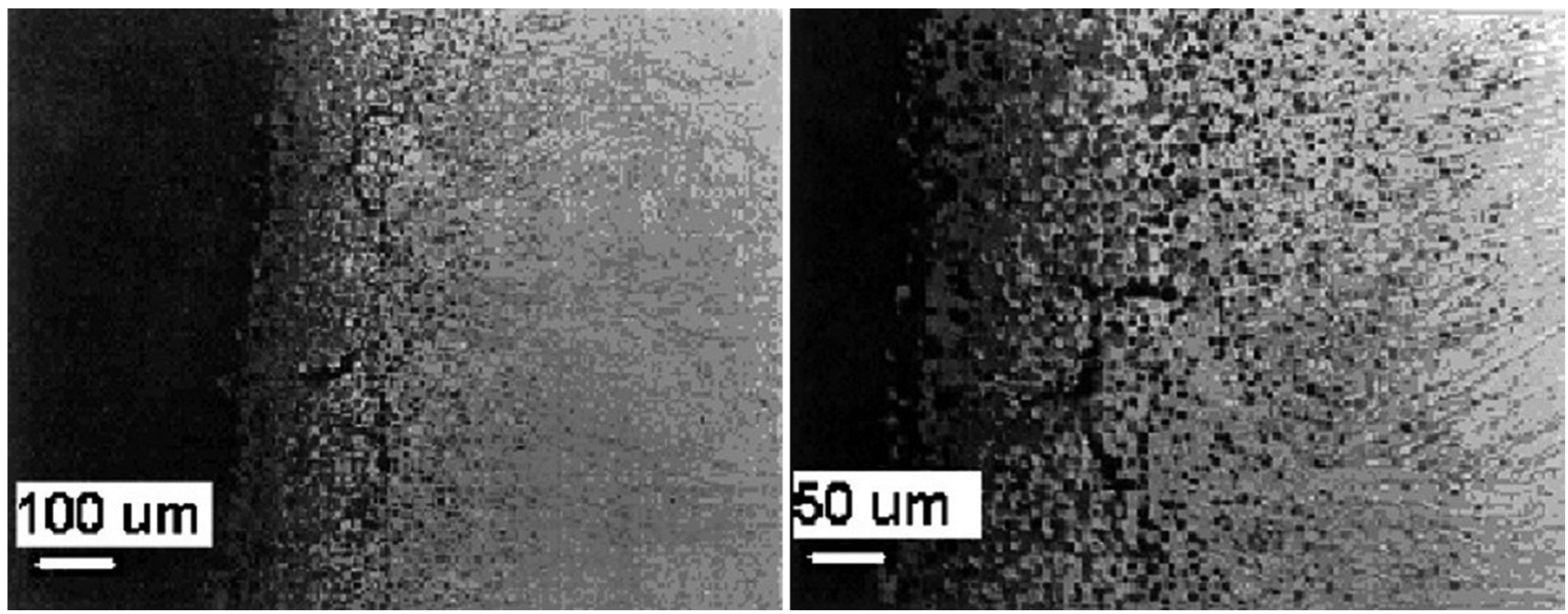

Figura 9. Micrografias da seção transversal da amostra de oxidação da liga 3 após ensaio de oxidação ao ar a $1200^{\circ} \mathrm{C}$ por 5 horas [ 12 , I3].
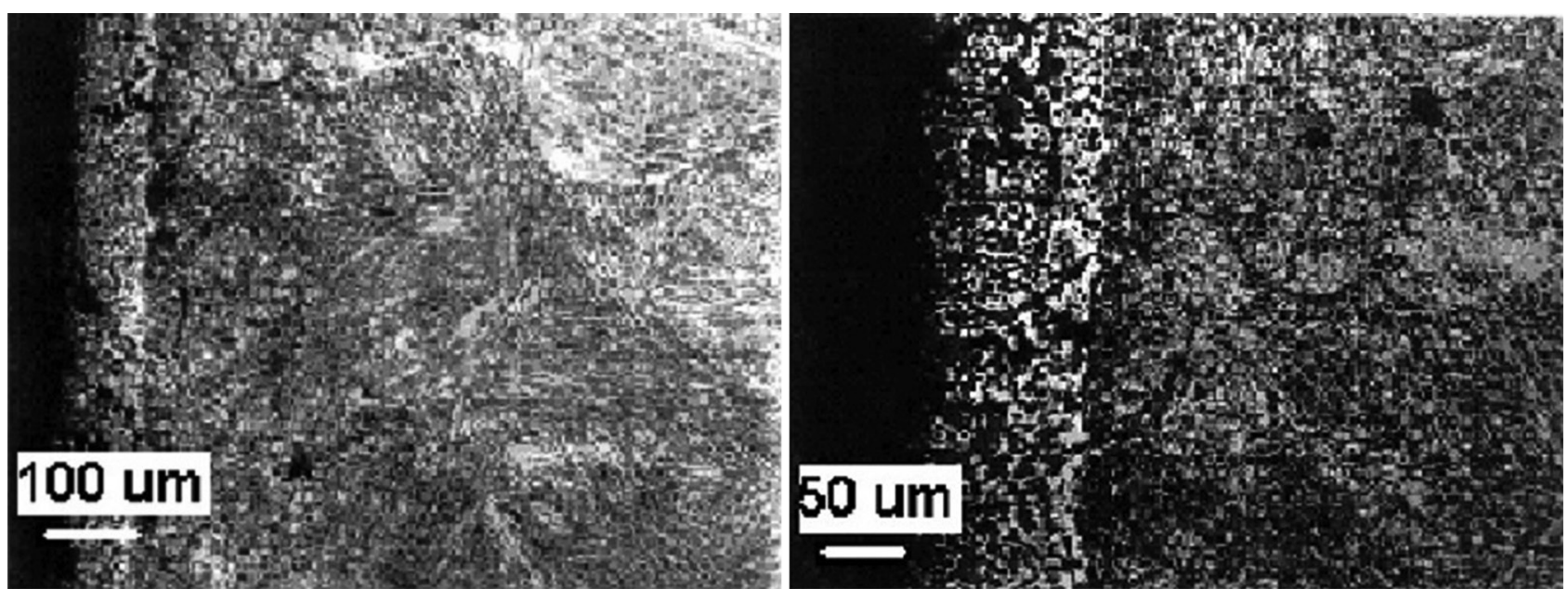

Figura 10. Micrografias da seção transversal da amostra de oxidação da liga 4 após ensaio de oxidação ao ar a $1200^{\circ} \mathrm{C}$ por 5 horas [ 12 , I3].
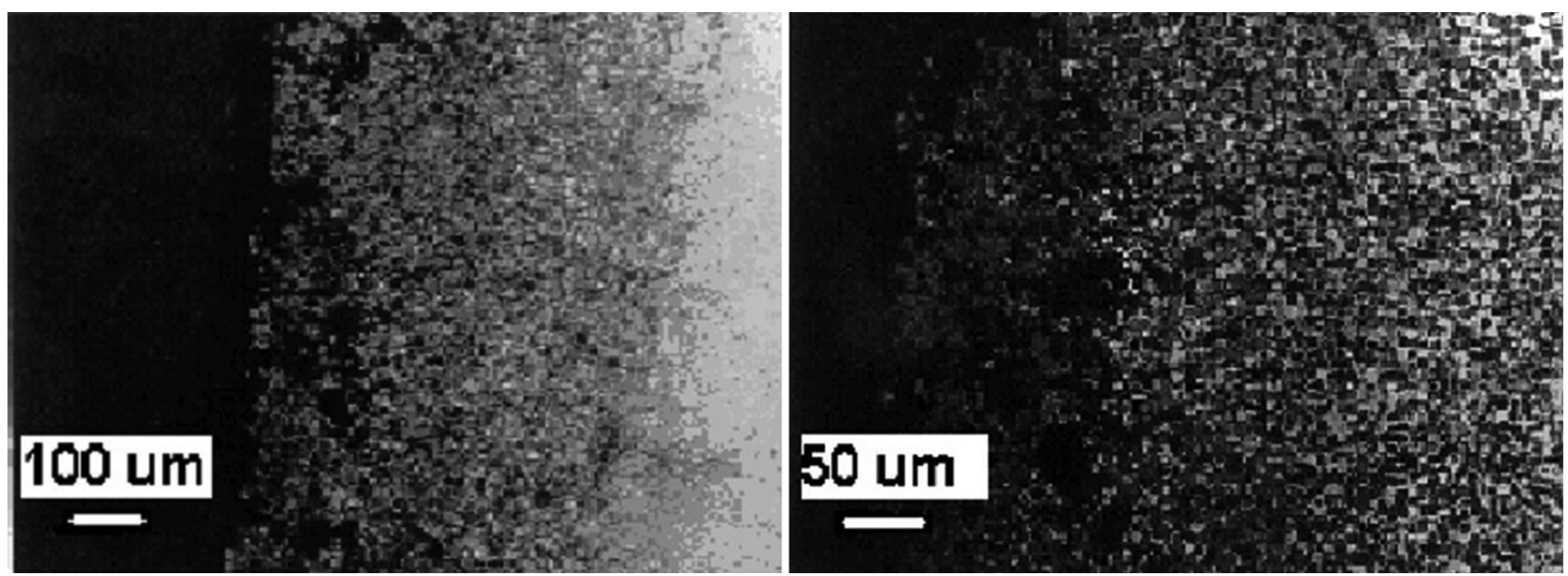

Figura I I. Micrografias da seção transversal da amostra de oxidação da liga 5 após ensaio de oxidação ao ar a $1200^{\circ} \mathrm{C}$ por 5 horas [ I2, I3]. 


\section{CONCLUSÃO}

a) A liga 4, mais rica em molibdênio, foi a única a apresentar austenita após o tratamento térmico de homogeneização, confirmando que o molibdênio abaixa a temperatura Ms.

b) O material solubilizado e encruado, quando submetido ao tratamento térmico de envelhecimento, endurece mais rápido e atinge valores de dureza maiores que o material solubilizado.

c) Os óxidos formados para as cinco ligas estudadas são extremamente reativos a alta temperatura.

d) $O$ aumento no teor de molibdênio na faixa de 7,5 a $15 \%$ melhora, significativamente, a resistência à oxidação.

\section{REFERÊNCIAS}

I Rohrbach K, Schmidt M. Maraging steels. In: Metals Handbook. I0th ed. Materials Park, Ohio: ASM; 1990. p. 793-800. (v. I).

2 Schmidt M, Rohrbach K. Heat treatment of maraging steels. In: Metals Handbook. IOth ed. Materials Park, Ohio: ASM; 1991. p. 219-228. (v. 4).

3 Floreen S. Maraging steels. In: Metals Handbook. 9th ed. Materials Park, Ohio: ASM; 1978. p. 445-452. (v. I).

4 Orsini MB. Efeito de um tratamento térmico de homogeneização na microestrutura e resistência ao impacto do aço forjado Maraging 18\%Ni, grau 1900MPa [dissertação de mestrado]. São Paulo: Escola Politécnica da USP; 1987.

5 Viswanathan UK, Dey GK, Asundi MK. Precipitation hardening in 350 grade maraging steel. Metallurgical Transactions A. 1993;24A:2429-2442.

6 Vasudevan VK, Kim SJ, Wayman CM. Precipitation reactions and strengthening behavior in $18 \mathrm{Wt}$ Pct nickel maraging steels. Metallurgical Transactions A. 1990; vol 2IA:2655-2668.

7 Sha W, Cerezo A, Smith GDW. Phase chemistry and precipitation reactions in Maraging steels: part I. Introduction and study of co-containing c-300 steel. Metallurgical Transactions A. 1993;24A:I22I-I 232.

8 Sha W, Cerezo A, Smith GDW. Phase chemistry and precipitation reactions in Maraging steels: part 2. Co-free T-300 steel. Metallurgical Transactions A. 1993;24A:1233-1239.

9 Sha W, Cerezo A, Smith GDW. Phase chemistry and precipitation reactions in Maraging steels: part 3. Model alloys. Metallurgical Transactions A. 1993;24A:I24I-1249.

10 Sha W, Cerezo A, Smith GDW. Phase chemistry and precipitation reactions in maraging steels: part 4. Discussion and conclusion. Metallurgical Transactions A. 1993;24A:I25I-I 256.

II Hornborgen E, Rittner K. Development of thermo-mechanical treatments of a maraging steel for yield strengths above 3 GPa. Steel Research. 1987;58:172-I77.

12 Vicente AA, Padilha AF, Ito HL. Caracterização das diversas etapas de processamento de aços maraging do tipo Fe- I4,5\%Co-13,5\%Ni-7,5 a 15\%Mo-Ti-Al [monografia]. São Paulo: EPUSP - PMT; 1995.

13 Vicente AA, Giusepone GA, Padilha AF. Efeito do molibdênio no comportamento de oxidação a alta temperatura ao ar de aços maraging de ultra alta resistência mecânica. In: 55 Congresso Anual da ABM. Rio de Janeiro; 2000.

14 Hume-Rothery W. Estrutura das ligas de ferro. São Paulo: Edgard Blücher; 1968.

15 Greyling CJ, Kotzé IA, Viljoen PE. The kinectics of oxide film growth on Maraging steel as described by space-charge effects. Surface and Interface Analysis. 1990; 16(I-12):293-298.

Recebido em: 16 Jun. 2014

Aceito em: 31 Jul. 2015 